University of Nebraska - Lincoln

DigitalCommons@University of Nebraska - Lincoln

$11-25-2006$

\title{
The all boron carbide diode neutron detector: Comparison with theory
}

\author{
A. N. Caruso \\ University of Nebraska-Lincoln, carusoan@umkc.edu \\ Peter A. Dowben \\ University of Nebraska-Lincoln, pdowben@unl.edu \\ S. Balkir \\ North Dakota State University, sbalkir2@unl.edu \\ Nathan Schemm \\ University of Nebraska-Lincoln \\ Kevin Osberg \\ University of Nebraska-Lincoln \\ See next page for additional authors
}

Follow this and additional works at: https://digitalcommons.unl.edu/physicsdowben

Part of the Physics Commons

\footnotetext{
Caruso, A. N.; Dowben, Peter A.; Balkir, S.; Schemm, Nathan; Osberg, Kevin; Fairchild, R.W.; Barrios Flores, Oscar; Balaz, Snjezana; Harken, A.D.; Robertson, Brian W.; and Brand, Jennifer I., "The all boron carbide diode neutron detector: Comparison with theory" (2006). Peter Dowben Publications. 173.

https://digitalcommons.unl.edu/physicsdowben/173

This Article is brought to you for free and open access by the Research Papers in Physics and Astronomy at DigitalCommons@University of Nebraska - Lincoln. It has been accepted for inclusion in Peter Dowben Publications by an authorized administrator of DigitalCommons@University of Nebraska - Lincoln.
} 


\section{Authors}

A. N. Caruso, Peter A. Dowben, S. Balkir, Nathan Schemm, Kevin Osberg, R.W. Fairchild, Oscar Barrios Flores, Snjezana Balaz, A.D. Harken, Brian W. Robertson, and Jennifer I. Brand 
Published in Materials Science and Engineering: B 135:2 (November 25, 2006), pp. 129-133. doi:10.1016/j.mseb.2006.08.049 Copyright (C) 2006 Elsevier B.V. Used by permission. http://www.sciencedirect.com/science/journal/09215107

\title{
The all boron carbide diode neutron detector: Comparison with theory
}

\author{
A.N. Caruso ${ }^{\text {a, b, c, d, P.A. Dowben }}$, b, *, S. Balkirb, e, Nathan Schemm ${ }^{\text {, e }}$, Kevin Osberg ${ }^{\text {b, e }}$, R.W. Fairchild ${ }^{\mathrm{f}}$, \\ Oscar Barrios Flores ${ }^{b, c}$, Snjezana Balaz ${ }^{\text {, c }}$, A.D. Harken ${ }^{\text {b, g, B.W. Robertson }}{ }^{\text {b, g }}$ and J.I. Brand ${ }^{\text {, c }}$
}

${ }^{\text {a }}$ Department of Physics and Astronomy, Behlen Laboratory of Physics, University of Nebraska-Lincoln, P.O. Box 880111, Lincoln, NE 68588-0111

${ }^{\mathrm{b}}$ Nebraska Center for Materials and Nanoscience, 116 Brace Laboratory, University of Nebraska-Lincoln, P.O. Box 880111, Lincoln, NE 68588-0111

${ }^{\mathrm{c}}$ College of Engineering, N245 Walter Scott Engineering Center, 17th Vine Street, University of Nebraska-Lincoln, Lincoln, NE 68588-0511

${ }^{\mathrm{d}}$ Center for Nanoscale Science and Engineering, North Dakota State University, Fargo, ND 58102

${ }^{\mathrm{e}}$ Department of Electrical Engineering, College of Engineering, 237N Walter Scott Engineering Center, 17th Vine Street, University of Nebraska-Lincoln, Lincoln, NE 68588-0511

${ }^{\mathrm{f}}$ Department of Physics and Astronomy, Nebraska Wesleyan University, Lincoln, NE 68504-2794

g Department of Mechanical Engineering, College of Engineering, N124 Walter Scott Engineering Center, 17th Vine Street, University of NebraskaLincoln, Lincoln, NE 68588-0656

\begin{abstract}
A boron carbide diode detector, fabricated from two different polytypes of semiconducting boron carbide, will detect neutrons in reasonable agreement with theory. Small deviations from the model calculations occur due to the detection efficiencies of the ${ }^{10} \mathrm{~B}$ capture products Li plus $\alpha$ sum signal differing somewhat from expectation in the thin diodes. The performance of the all boron carbide neutron detector does depart from the behavior of devices where a boron rich neutron capture layer is distinct from the diode charge collection region (i.e. a conversion layer solid state detector), as is expected.
\end{abstract}

Keywords: Boron carbide diodes, Neutron detection, Pulse counting

Semiconducting boron carbide represents a new class of semiconducting materials with potential applications in neutron detection and radioactive decay calorimetry [1-7]. Boron carbide thin film diodes and devices have begun to attract attention as potentially highly efficient solid state neutron detectors [8-10]. This interest has been spurred on because ${ }^{10} \mathrm{~B}$ has a high cross-section (approximately 3800 barns) for neutrons at lower energies $(\sim 25 \mathrm{meV})$, based on the ${ }^{10} \mathrm{~B}(\mathrm{n}, \alpha){ }^{7} \mathrm{Li}$ neutron capture reactions:

$$
{ }^{10} \mathrm{~B}+\mathrm{n} \rightarrow{ }^{7} \mathrm{Li}(0.84 \mathrm{MeV})+{ }^{4} \mathrm{He}(1.47 \mathrm{MeV})+\gamma(0.48 \mathrm{MeV})
$$

${ }^{10} \mathrm{~B}+\mathrm{n} \rightarrow{ }^{7} \mathrm{Li}(1.02 \mathrm{MeV})+{ }^{4} \mathrm{He}(1.78 \mathrm{MeV}) \quad(6 \%)$

Perhaps because of confusion between dielectric and semiconducting polytypes of boron carbide and boron carbides with only modest sheet resistance, there has been considerable controversy as to whether an all boron carbide semiconducting diode can act as a neutron detector $[7,9,11,12]$. This controversy has been somewhat addressed by the fabrication of all boron carbide neutron detectors $[4,6]$ from semiconducting polytypes of boron carbide.

An all boron carbide solid state diode detector should exhibit a distinctly different pulse height spectrum [13] than a device where the neutron capture is not an integral part of the diode: a device where a thin boron rich layer is instead placed adjacent to a diode (commonly called a conversion layer device) [12-15]. A number of boron based conversion layer neutron detector diode devices have been fabricated $[5,12,16-$ $24]$, as well as some heterojunction diode detectors [1-3,5]. Both the heterojunction diodes (where one side of the diode, usually the p-layer, contains boron) and conversion layer devices have pulse height spectra characteristic of strong contributions from $0.84 \mathrm{MeV}^{7} \mathrm{Li}$ and $1.47 \mathrm{MeV}^{4} \mathrm{He}$ (1), with weak- 
er contributions from $1.02 \mathrm{MeV}^{7} \mathrm{Li}$ and $1.78 \mathrm{MeV}^{4} \mathrm{He}(2)[1-$ $3,5,9,10,12-24]$.

As discussed herein, these strong pulse height spectral features should not be and are not as clearly evident with an all boron carbide diode because portions of both the ${ }^{7} \mathrm{Li}$ and ${ }^{4} \mathrm{He}$ ( $\alpha$ particle) tracks should be recovered [13]. In other words, some detection of the sum of the ${ }^{7} \mathrm{Li}$ and ${ }^{4} \mathrm{He}(\alpha$ particle) tracks (commonly referred to as the sum peaks) should be characteristic of an all boron carbide diode.

Three types of all boron carbide diode devices have been reported. There is the conventional homojunction diode where a transition metal dopant is used to dope the semiconducting boron carbide n-type or p-type. The homojunction diode has seen effective realization by doping the semiconducting boron carbide during film growth through plasma-enhanced chemical vapor deposition (PECVD) from a suitable carborane [25, 26]. A few all boron carbide devices [4,6], generally from semiconducting boron carbides formed from the decomposition of molecular precursors such as from the decomposition of closo-dicarbadodecaboranes: closo-1,2-dicarbadodecaborane (orthocarborane, $\mathrm{C}_{2} \mathrm{~B}_{10} \mathrm{H}_{12}$ ) and closo-1,7-dicarbadodecaborane (metacarborane, $\mathrm{C}_{2} \mathrm{~B}_{10} \mathrm{H}_{12}$ ) [4]. This latter all boron carbide device has been described as a heteroisomeric diode [4], as two electronically different semiconducting boron carbide polytypes are used, and the diode is not quite a conventional homojunction diode, although the two semiconducting boron carbides are compositionally similar. More recently, an all boron carbide heterojunction diode has been fabricated using two very different types of boron carbide [27]. All three types of diodes behave reasonably similar, with similar diode characteristics.

Following the procedure described elsewhere [25, 26, $28,29]$, the $\mathrm{p}-\mathrm{n}$ homojunctions were formed by depositing boron carbide thin films in a custom designed parallel plate 13.56 MHz radio frequency PECVD reactor. The source molecule gas closo-1,2-dicarbadecaborane (orthocarborane) was used to grow the slightly p-type boron carbide while nickelocene $\left(\mathrm{Ni}\left(\mathrm{C}_{5} \mathrm{H}_{5}\right)_{2}\right)$ was used to introduce nickel into the semiconducting boron carbide film grown in the plasma reactor using orthocarborane (closo-1,2-dicarboadodecaborane $\left.\left(\mathrm{C}_{2} \mathrm{~B}_{10} \mathrm{H}_{12}\right)\right)$ film. The inclusion of nickel, from nickelocene $\left(\mathrm{Ni}\left(\mathrm{C}_{5} \mathrm{H}_{5}\right)_{2}\right)$ simultaneously introduced into the plasma reactor with orthocarborane (closo-1,2-dicarboadodecaborane $\left.\left(\mathrm{C}_{2} \mathrm{~B}_{10} \mathrm{H}_{12}\right)\right)$ film, resulted in an effective n-type-boron carbide $[25,26,28,29]$. All boron carbide $\mathrm{p}-\mathrm{n}$ junction diodes were also fabricated by chemical vapor deposition from two different isomers of closo-dicarbadodecaborane (closo-1,2-dicarbadodecaborane (orthocarborane, $\mathrm{C}_{2} \mathrm{~B}_{10} \mathrm{H}_{12}$ ) and closo-1,7dicarbadodecaborane (metacarborane, $\mathrm{C}_{2} \mathrm{~B}_{10} \mathrm{H}_{12}$ )) that differ only by the carbon position within the icosahedral cage. The diodes were constructed using the process of PECVD (plasma enhanced chemical vapor deposition) as described for both heterojunction $[1,25-30]$ and homojunction diodes $[25,26]$ of boron carbide, but with only carboranes and argon as the plasma reactor gases. The boron carbide semiconductor films formed after decomposition are clearly self doping materials, since the deposition and decomposition involves only the metacarborane and orthocarborane source molecules (n-type and p-type, respectively), as discussed elsewhere [4]. In fabricating the all boron carbide heteroisomeric or heteropolytype diodes for these studies, no transition metal impurity dopants were introduced as was necessary for the more conventional homojunction boron carbide based diodes [25, 26].

A homojunction diode $250 \mathrm{~nm}$ thick (fabricated through the PECVD decomposition of closo-1,2-dicarbadodecaborane and nickel doped orthocarborane) compares well with a heteroisomeric diode fabricated from the PECVD decomposition of closo-1,2-dicarbadodecaborane (orthocarborane, $\mathrm{C}_{2} \mathrm{~B}_{10} \mathrm{H}_{12}$ ) and closo-1,7-dicarbadodecaborane (metacarborane, $\mathrm{C}_{2} \mathrm{~B}_{10} \mathrm{H}_{12}$ ), some $400 \mathrm{~nm}$ thick, as seen in Fig. 1. The PECVD deposition of boron carbide films from the latter two carboranes, as indicated above, resulting in a p-type and ntype semiconducting boron carbide as described in [4, 31].

In looking at the two semiconducting boron carbides formed from the PECVD decomposition of the different closodicarbadodecaboranes we note that, although the direct band gaps are very similar [32], their contribution to the depletion region of a diode is slightly different, as indicated in Fig. 2. Here we have plotted the turn on (onset or threshold) voltage relative to silicon for both types of boron carbide, in the heterojunction diode geometry. Nonetheless, the depletion region for a heteroisomeric diode is in the region of $2 \mu \mathrm{m}$ or more. Thus increasing the diode thickness to $2 \mu \mathrm{m}$ or more should result in an increase in detection efficiency, for very low neutron fluxes, in spite of the fact that the device is considerably

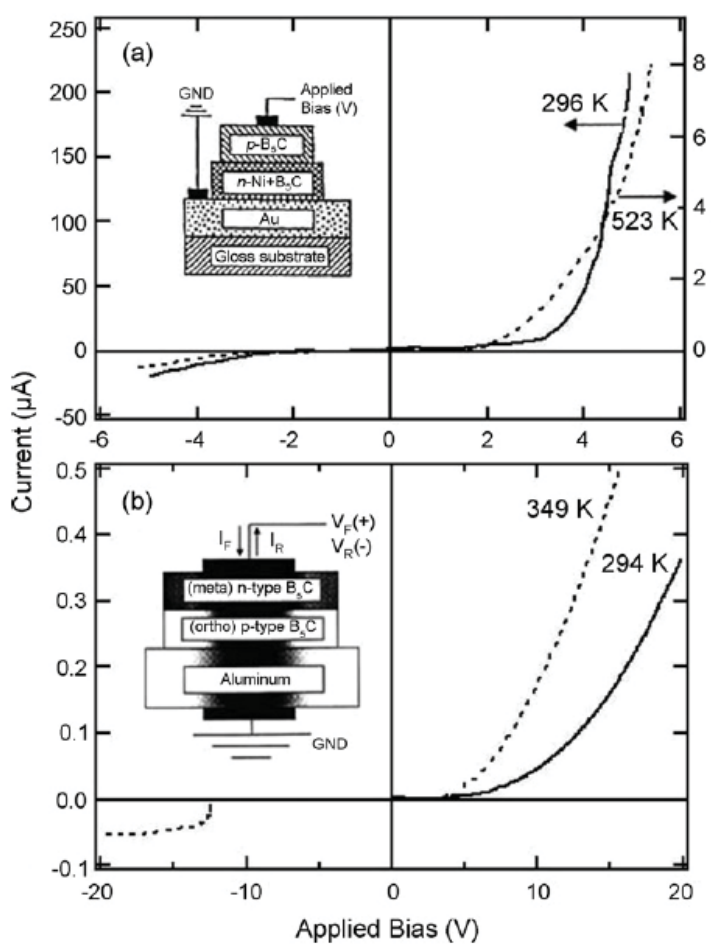

Figure 1. The temperature dependent characteristic $I(V)$ curves for an all boron carbide homojunction diode (a), formed through Ni doping of one boron carbide layer, and an all boron carbide heteroisomeric diode fromed from two different polytypes of semiconducting boron carbide (b). 


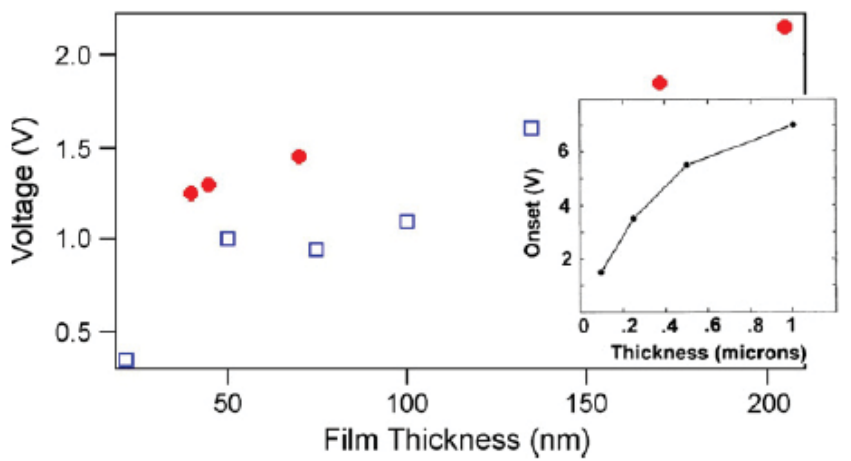

Figure 2. The silicon to semiconducting heterojunction diode onset voltages with n-type boron carbide (filled) and p-type boron carbide (open squares), as a function of boron carbide film thickness. The trend for larger thickness is shown in the inset.

more resistive, as expected from the high boron carbide resistivities illustrated in Fig. 3, and the increase in the voltage for on set of a forward bias current, as indicated in Fig. 4.

To model thermal neutron detection for the all boron carbide devices (as discussed in detail elsewhere [13, 33]), we

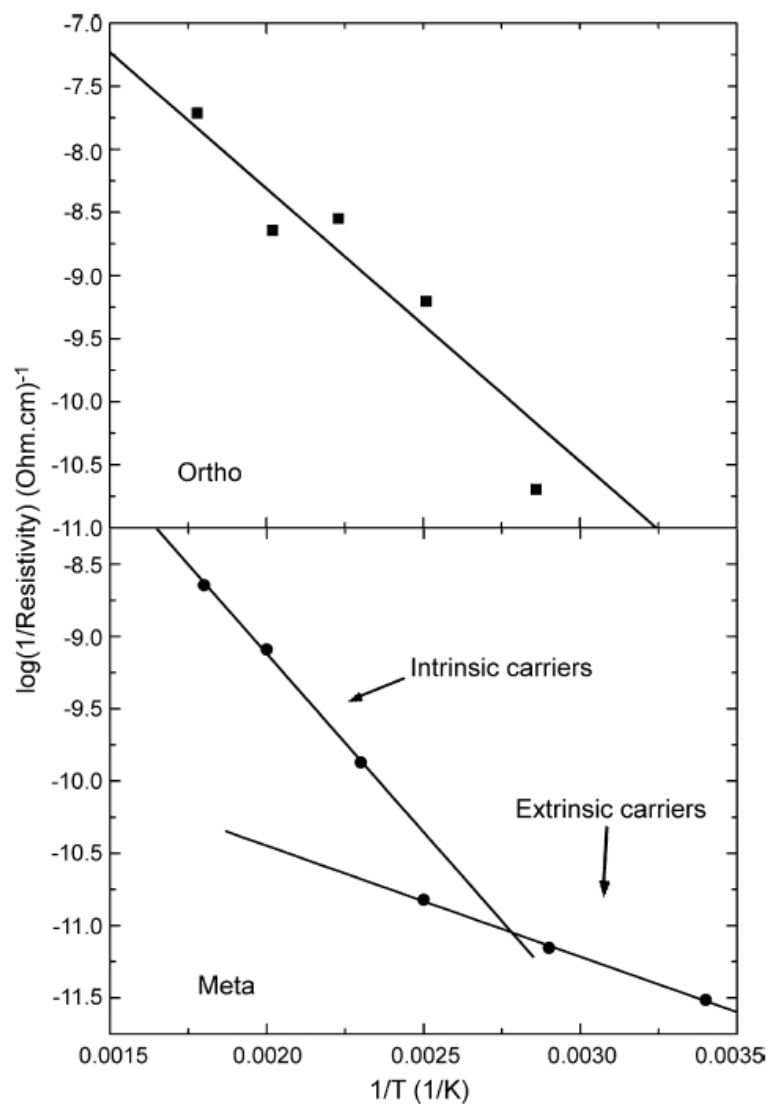

Figure 3. The logarithmic function of inverse of the measured resistance as a function of the inverse of temperature for film fabricated from (top) closo-1,2-dicarbadodecaborane (orthocarborane, $\mathrm{C}_{2} \mathrm{~B}_{10} \mathrm{H}_{12}$ ) and (bottom) closo-1,7-dicarbadodecaborane (metacarborane, $\mathrm{C}_{2} \mathrm{~B}_{10} \mathrm{H}_{12}$ ). The two distinct regions indicated for closo-1,7-dicarbadodecaborane (metacarborane, $\mathrm{C}_{2} \mathrm{~B}_{10} \mathrm{H}_{12}$ ) correspond to intrinsic carriers at high temperature, and extrinsic carriers at low temperature, respectively [34].

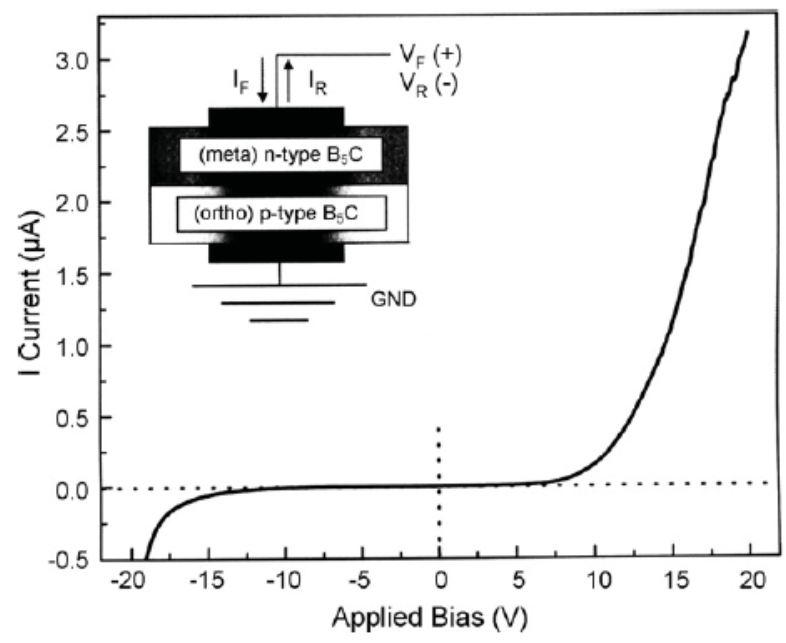

Figure 4. The $I(V)$ characteristic curve of a $2 \mu \mathrm{m}$ thick p-type boron carbide semiconducting polytype to n-type boron carbide semiconducting polytype diode at $295 \mathrm{~K}$, as described in [4], and in the text. The inset is a schematic of the diode construction.

employed constant straight-paths for the ${ }^{7} \mathrm{Li}$ and ${ }^{4} \mathrm{He}$ capture products which are assumed to be emitted isotropically in opposite directions. The ${ }^{7} \mathrm{Li}$ and ${ }^{4} \mathrm{He}$ capture products lose kinetic energy along these paths, leading to charge pulse production. The probabilities for capture of a normally incident thermal neutron within a $1 \mu \mathrm{m}$ thick boron carbide layer results in deposition of energies, as plotted in Fig. 5b. The general decrease with increasing energy deposition, punctuated by sum pulse height peaks at 2.31 and $2.8 \mathrm{MeV}$ corresponding to $\mathrm{n}+{ }^{10} \mathrm{~B} \rightarrow{ }^{7} \mathrm{Li}+{ }^{4} \mathrm{He}+\gamma$ and $\mathrm{n}+{ }^{10} \mathrm{~B} \rightarrow{ }^{7} \mathrm{Li}+{ }^{4} \mathrm{He}$, respectively (capture reactions (1) and (2), respectively), are the result of the geometry of the device, as just indicated. These expectations are largely observed in experiment, which of course additionally must involve tailing and broadening due to incomplete charge collection and electronic noise.

The detection of charge pulses created by neutron capture has been performed by means of a hand held instrumentation system developed for this purpose. The front-end of the system consists of a custom designed analog CMOS integrated circuit that acts as a charge sensitive amplifier (CSA). The amplifier is essentially a lossy integrator with a feedback capacitor bank for charge to voltage conversion. The capacitor bank is digitally programmable via a user interface so that different conversion gain settings can be utilized during experiments. We used a $15 \mathrm{pF}$ capacitor setting for the charge sensitive amplifier during the measurements reported here and the boron carbide diodes were reverse biased with $3 \mathrm{~V}$. Once the charge pulses are converted to voltage, they are sampled with a 12 -bit $\mathrm{A} / \mathrm{D}$ converter at a rate of 1.5 mega samples/s. This permits the implementation of neutron event counting, storage, and pulse height spectra gathering via digital signal processing techniques within the hand held unit. The recorded data was downloaded to a PC.

Heteroisomeric boron carbide diodes, formed from metacarborane and orthocarborane decomposition, are sensitive to neutrons, as seen in Fig. 5a. Thermal neutrons were generated from a paraffin moderated plutonium-beryllium source. 


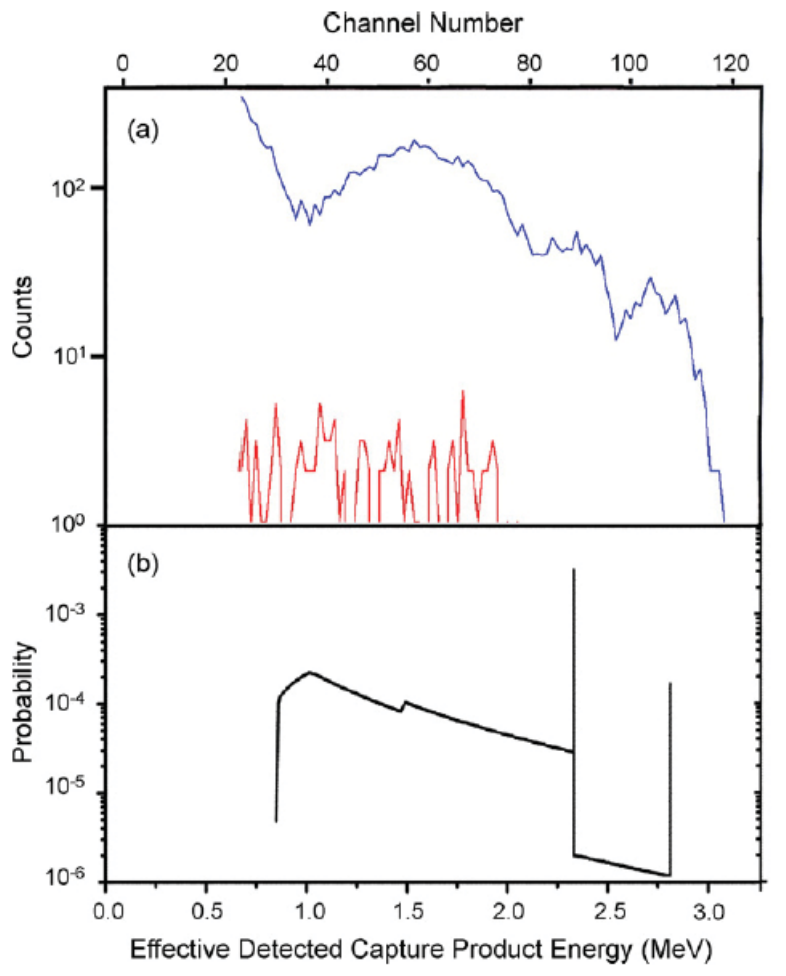

Figure 5. The experimental neutron pulse height spectrum (a) for a $2 \mu \mathrm{m}$ thick all boron carbide diode (blue) is compared to the probability spectrum (b) for energy deposition by the capture products from a neutron normally incident on an all $\mathrm{B}_{10} \mathrm{C}_{2}$ detector $2 \mu \mathrm{m}$ thick. Blocking neutron flux through the use of a $\mathrm{Cd}$ foil result in few counts (red in (a)).

The signal was observed above background. This is definitely not the spectrum expected of a boron conversion layer device. There are no strong signatures of $0.84 \mathrm{MeV}^{7} \mathrm{Li}$ and $1.47 \mathrm{MeV}$ ${ }^{4} \mathrm{He}$ pulse heights, which we do observe from heterojunction devices. The pulse height spectra were readily calibrated through a comparison with a conversion layer device, whose characteristic $\mathrm{Li}$ and $\mathrm{He}$ decay fragment capture features [1-3, $5,6,12-24]$ provide an excellent energy calibration.

The results shown in Fig. 5 are for a rather thin $(2 \mu \mathrm{m})$ diode that was not fabricated with enriched ${ }^{10} \mathrm{~B}$, but rather with natural abundance $20 \%{ }^{10} \mathrm{~B}$ and $80 \%{ }^{11} \mathrm{~B}$. There is clearly incomplete charge sweep out for many events, which results in a loss of the significant and very sharp contributions from the expected full energy (sum) peaks at $2.31 \mathrm{MeV}$ in particular. This is evident from the fact that the counts expected from the $2.31 \mathrm{MeV}$ sum peak and the $2.8 \mathrm{MeV}$ do not scale as expected from the theory $[12,33]$. The fact that the count rate does not scale in complete agreement with our theoretical predictions is evident in Fig. 5. These differences, between the real devices and our predictions, are in fact greater with the thinner boron carbide diodes, so fabricating much thicker all boron carbide diodes, with large depletion regions, is indicated, so long as complete charge collection can still be obtained in spite of the greater resistivity of such devices. Bias could play a role, as noted elsewhere [6], and this should be explored for the devices described here. Thinner all boron carbide diodes show even less structure in the pulse height spectra and fewer counts at larger pulse heights, consistent with incomplete charge collection in thinner diode structures expected from model calculations $[12,33]$. The absence of the full energy (sum) peaks is also noted in other very thin all boron carbide devices [6].

By altering film thickness of the all boron carbide diodes, device performance was altered and the pulse height spectra changed dramatically. This behavior does suggest that the boron carbide diodes are the major source for neutron capture and pulse generation, not the amplifier circuit nor other data acquisition electronics. The changing response to the different thickness of all boron carbide diodes does not completely discount any influence of neutron flux on the first amplifier FET, however. We can assign the neutron detection more conclusively to the boron carbide diode by noting that by covering the all boron carbide diode alone (not the electronics) with a $4 \mathrm{~mm}$ thick $\mathrm{Cd}$ foil (blocking or reflecting the epithermal neutrons from reaching the detector) dramatically decreases the count rate to only a few counts, as indicated in the red curve in Fig. 5a. This, and the changing response of different thicknesses of boron carbide semiconductor diodes, allows us to conclude that effects of neutron capture by the charge amplifier and pulse counting electronics are largely insignificant.

The $\mathrm{Cd}$ neutron blocker should produce gamma radiation. The de-excitation of ${ }^{114} \mathrm{Cd}$ contains many gamma rays emitted in cascades [9], which do not appear to be detected in our device - consistent with an absence of pulses caused by a radioactive ${ }^{60} \mathrm{Co}$ gamma emitter source. In effect, these all boron carbide devices appear to largely gamma blind. The small number of counts, after placing the $\mathrm{Cd}$ foil in position may also be the result of unsuccessfully moderated non-thermal neutrons for the $\mathrm{PuBe}$ source. The boron carbide heterojunctions diodes were also found to be insensitive to a ${ }^{60} \mathrm{Co}$ gamma source $[1,2]$.

The heteroisomeric class of all boron carbide diodes [4] is somewhat different from both "all" boron carbide heterojunction [27] and homojunction diodes [25, 26] that exploit semiconducting boron carbides. The heteroisomeric class of all boron carbide diodes provides a pulse height spectra from neutron capture that is distinctly different from heterojunction formed with boron carbide and a dissimilar material and conversion layer solid state detectors $[1-3,5,6,12-24]$ based upon boron and boron compounds. The pulse height spectra for the all boron carbide diode structures should differ from semiconductor heterojunction formed with boron rich semiconductor and a dissimilar material and conversion layer solid state detectors because the large depletion regions and because both sides of the $\mathrm{p}-\mathrm{n}$ junction contain a boron rich semiconductor, as in the examples discussed here.

There remain many challenges. An accurate assessment of the detector efficiency is still needed; such an effort requires fabricating a number of all boron carbide diode detectors with a range of detection areas, as ascertaining the actual detection area of each diode remains something of a challenge. Nonetheless, it remains clear that this class of boron carbide semiconductor diode devices are indeed effective neutron detectors, along with other all boron carbide or boron rich semicon- 
ductor diode structures. The heteroisomeric diodes can act as all boron carbide neutron detectors in reasonable agreement with expectations, even without isotopic enrichment.

\section{Acknowledgements}

This research was supported by the Office of Naval Research, the Defence Advanced Research Project Agency (DARPA) and the U.S. Department of Energy National Nuclear Security Administration Office of Non-proliferation Research and Engineering (NA-22) through Pacific Northwest National Laboratory. The authors would like to acknowledge a number of helpful discussions with Karl Pitts.

\section{References}

[1] B.W. Robertson, S. Adenwalla, A. Harken, P. Welsch, J.I. Brand, P.A. Dowben and J.P. Claassen, Appl. Phys. Lett. 80 (2002), pp. 3644-3646.

[2] B.W. Robertson, S. Adenwalla, A. Harken, P. Welsch, J.I. Brand, J.P. Claassen, N.M. Boag and P.A. Dowben In: I.S. Anderson and B. Guérard, Editors, Advances in Neutron Scattering Instrumentation, Proc. SPIE 4785 (2002), pp. 226-233.

[3] S. Adenwalla, R. Billa, J.I. Brand, E. Day, M.J. Diaz, A. Harken, A. McMullen-Gunn, R. Padmanabhan and B.W. Robertson, Penetrating Radiation Systems and Applications V, Proc. SPIE 5199 (2003), pp. 70-74.

[4] A.N. Caruso, R.B. Billa, S. Balaz, J.I. Brand and P.A. Dowben, J. Phys. Condens. Matter 16 (2004), pp. L139-L146.

[5] A.D. Harken, E.E. Day, B.W. Robertson and S. Adenwalla, Jpn. J. Appl. Phys. 44 (2005), pp. 444-445.

[6] E. Day, M.J. Diaz and S. Adenwalla, J. Phys. D: Appl. Phys. 39 (2006), p. 2920.

[7] D. Emin and T.L. Aselage, J. Appl. Phys. 97 (2005), p. 013529.

[8] D.N. McIlroy, J. Phys. Condens. Matter 16 (2004), pp. V13V14.

[9] Z.W. Bell, D.A. Carpenter, S.S. Cristy, V.E. Lamberti, A. Burger, B.F. Woodfield, T. Niedermayr, I.D. Hau, S.E. Labov, S. Friedrich, W.G. West, K.R. Pohl and L. van der Berg, Phys. Stat. Solidi c2 (2005), pp. 11592-11605.

[10] A. Owens and A. Peacock, Nucl. Inst. Meth. Phys. Res. A 531 (2004), pp. 18-37.

[11] P.M. Martin, Vac. Coat. Technol. (2004), pp. 6-11.

[12] D.S. McGregor and J.K. Shultis, Nucl. Inst. Meth. Phys. Res. A 517 (2004), p. 180.

[13] C. Lundstedt, A. Harken, E. Day, B.W. Robertson and S. Adenwalla, Nucl. Inst. Meth. Phys. Res. A 562 (2006), p. 380.

[14] J.K. Shultis and D.S. McGregor, IEEE Trans. Nucl. Sci. 53 (2006), p. 1659.
[15] S. Park, Y.K. Kim, J.H. Ha and J.K. Kim, J. Korean Phys. Soc. 47 (2005), p. 586.

[16] N. Sato, O. Ishiwata, Y. Seki and A. Ueda, Jpn. J. Appl. Phys. 29 (1990), p. 2526.

[17] C.A. Baker, K. Green, M.G.D. van der Grinten, P.S. Iaydjiev, S.N. Ivanov, S. Al-Ayoubi, P.G. Harris, J.M. Pendlebury, D.B. Shiers and P. Geltenbort, Nucl. Inst. Meth. A 487 (2002), p. 511.

[18] A. Rose, Nucl. Inst. Meth. 52 (1967), p. 166.

[19] A.J. Peurrung, Nucl. Inst. Meth. A 443 (2000), p. 400.

[20] D.S. McGregor, M.D. Hammig, Y.H. Yang, H.K. Gersch and R.T. Klann, Nucl. Inst. Meth. A $\mathbf{5 0 0}$ (2003), p. 272.

[21] D.S. McGregor, R.T. Klann, H.K. Gersch, E. Ariesanti, J.D. Sanders and B. van der Elzen, IEEE Trans. Nucl. Sci. 49 (2002), p. 1999.

[22] H.K. Gersch, D.S. McGregor and P.A. Simpson, Nucl. Inst. Meth. A 489 (2002), p. 85.

[23] D.S. McGregor, R.T. Klann, H.K. Gersch and Y.H. Yang, Nucl. Inst. Meth. A 466 (2001), p. 126.

[24] D.S. McGregor, S.M. Vernon, H.K. Gersch, S.M. Markham, S.J. Wojtczuk and D.K. Wehe, IEEE Trans. Nucl. Sci. 47 (2000), p. 1364.

[25] S.-D. Hwang, N.B. Remmes, P.A. Dowben and D.N. McIlroy, J. Vac. Sci. Technol. B 14 (1996), p. 2957.

[26] S.-D. Hwang, K. Yang, P.A. Dowben, A.A. Ahmad, N.J. Ianno, J.Z. Li, J.Y. Lin, H.X. Jiang and D.N. McIlroy, Appl. Phys. Lett. 70 (1997), pp. 1028-1030.

[27] S. Balaz, D.I. Dimov, N.M. Boag, K. Nelson, B. Montag, J.I. Brand and P.A. Dowben, Appl. Phys. A 84 (2006), pp. 149-159.

[28] S.-D. Hwang, N. Remmes, P.A. Dowben and D.N. McIlroy, J. Vac. Sci. Technol. A 15 (1997), pp. 854-858.

[29] D.N. McIlroy, S.-D. Hwang, K. Yang, N. Remmes, P.A. Dowben, A.A. Ahmad, N.J. Ianno, J.Z. Li, J.Y. Lin and H.X. Jiang, Appl. Phys. A 67 (1998), p. 335.

[30] S.-D. Hwang, D. Byun, N.J. Ianno, P.A. Dowben and H.R. Kim, Appl. Phys. Lett. 68 (1996), pp. 1495-1497.

[31] A.N. Caruso, S. Balaz, B. Xu, P.A. Dowben, A.S. McMullenGunn, J.I. Brand, Y.B. Losovyj and D.N. McIlroy, Appl. Phys. Lett. 84 (2004), p. 1302.

[32] P. Lunca-Popa, J.I. Brand, S. Balaz, L.G. Rosa, N.M. Boag, M. Bai, B.W. Robertson and P.A. Dowben, J. Phys. D: Appl. Phys. 38 (2005), p. 1248.

[33] A.D. Harken, C.N. Lundstedt, E.E. Day, B.W. Robertson, IEEE Trans. Nucl. Sci., submitted for publication.

[34] C.C. Ilie, Snjezana Balaz, L.G. Rosa, J. Zhang, P. Lunca-Popa, C. Bianchetti, R. Tittsworth, J.I. Brand, B. Doudin and P.A. Dowben, Appl. Phys. A 81 (2005), pp. 1613-1618. 